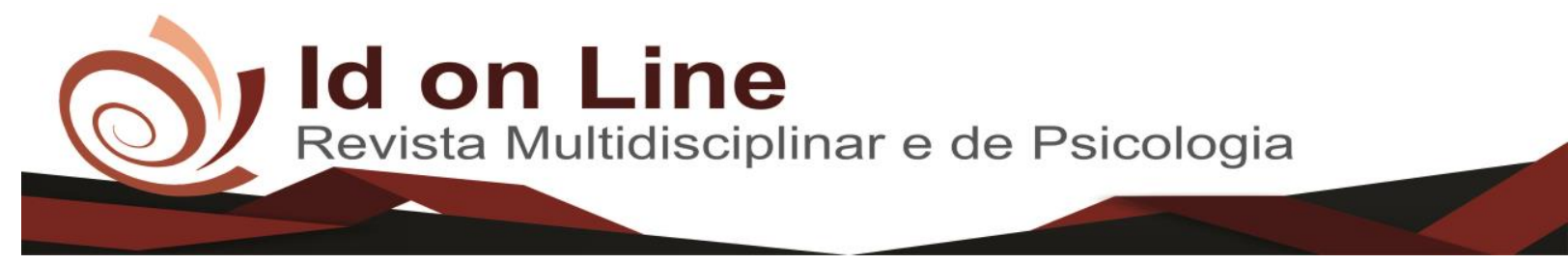

Artigo

\title{
Economia compartilhada aliado ao setor de serviços: uma revisão sistemática de trabalho brasileiros
}

\author{
Luiz Nayjhon de Souza Oliveira ${ }^{1}$ Antônio Raniel Silva Lima²
}

\begin{abstract}
Resumo: Com as transformações tecnológicas, veio a acessibilidade advinda desses meios, nasce então o consumo altruísta, a ideia de comprar a experiência e não a posse, dando alternativas a quem só tinha o tradicional. A economia compartilhada ou colaborativa como é chamada ao longo desse trabalho, é um mercado crescente e notório, traz consigo a ideia sustentável, preços competitivos, confiança, acessibilidade, e a opção para quem quer sair dos moldes ultrapassados e tradicionais. Esse tipo de consumo está cada vez mais no convívio das pessoas, e no Brasil, este mercado encontra-se em ascensão, embora presente no país, foi debatido ao longo dos anos a falta de trabalhos voltados ao tema. Esse trabalho cumpri o objetivo de verificar o direcionamento da literatura brasileira, sobre o tema economia compartilhada observando sua evolução. Para a coleta de conteúdo foi utilizado o "google acadêmico", e restringido o tema a duas ferramentas expoentes no meio compartilhado, o Uber, empresa de intermediação de serviços e negócios (SALMAN,2018). Airbnb, empresa de serviços paralelo ao hoteleiro (GURGEL, 2017). Escolhido um total de 15 resultados, aonde foi dividido as informações em sustentabilidade, mercado e regulamentação, características pertinentes a proposta deste trabalho, e que mostra a evolução dos mesmos no espaço de tempo entre 2015 e 2018 , dando relevância os últimos 4 anos. Com os resultados encontrados, pode se observar o crescimento acadêmico brasileiro relacionado o tema, mas em contrapartida encontram-se mais forte os debates no tocante a regulamentação e sua sustentabilidade.
\end{abstract}

Palavras Chave: Revisão sistemática. Economia compartilhada. Regulamentação. Sustentabilidade. Mercado.

\section{Shared Economy allied to the Service Sector: a Systematic Review of the Brazilian Work}

\begin{abstract}
With the technological transformations, came the accessibility coming from these means, then the altruistic consumption was born, the idea of buying the experience and not the possession, giving alternatives for those who only had the traditional. The shared or collaborative economy, as it is called throughout this work, is a growing and notorious market, brings with it the sustainable idea, competitive prices, trust, accessibility, and the option for those who want to get out of the outdated molds and Traditional. This type of consumption is increasingly in the conviviality of people, and in Brazil, this market is on the rise, although present in the country, has been debated over the years the lack of work focused on the theme. This work fulfilled the objective of verifying the direction of the Brazilian literature on the theme shared economy observing its evolution. For the content collection was used the "academic Google", and restricted the theme to two exponents tools in the shared environment,

the Uber, business and services intermediation Company (SALMAN,2018). Airbnb, a service company parallel to the Hotel (Gurgel, 2017). Chosen a total of 15 results, where was divided the information in sustainability, market and regulation, characteristics pertinent to the proposal of this work, and that shows the evolution of them in time between 2015 and 2018, giving relevance the last four years. With the results found, we can observe the Brazilian academic growth related to the theme, but on the other hand there are stronger debates regarding regulation and its sustainability.
\end{abstract}

Keywords: Systematic review. Shared economics. Regulation. Sustainability. Market.

${ }^{1}$ Graduando do curso de Administração do Centro Universitário Leão

Sampaio/Unileão_nayjhon1995@gmail.com

2 Professor especialista do Centro Universitário Leão Sampaio/Unileão_raniel@leaosampaio.edu.br 


\section{Introdução}

A economia compartilhada teve origem na década de 1990, nos Estados Unidos, impulsionada pelos avanços tecnológicos que propiciaram a redução dos custos das transações online ponto a ponto (SHIRKY, 2012). Esse processo de compartilhamento econômico possui algumas outras denominações, dentre elas a de economia colaborativa, pois também se refere a modelos de negócios baseados em comunidades on-line (SAMPAIO, 2017). O mundo tornouse mais dinâmico, mudanças constantes e mais rápidas, o surgimento e a posterior evolução da internet permitiram conectar o mundo inteiro, possibilitando comunicações de longa distância e em alta velocidade (PIERRE, 2016).

O compartilhamento é definido como um processo de distribuição e compartilhamento do que é nosso para os outros, ou daquilo que é de outro para uso nosso (SAMPAIO, 2017). Esse novo modelo é cada vez mais crescente no mundo das organizações e modelos de negócios, no contexto de economia compartilhada (GANSKY, 2010)

Para Soares et al. (2017) essas ferramentas influenciam o comportamento do consumidor, devido a forma de disponibilidade, e facilidade no acesso, atendendo assim as novas necessidades do mercado de serviços. Cada vez mais as pessoas procuram por experiencias autenticas e inusitadas, que possam ser compartilhados das outras pessoas (ALBERTINI, 2017).

Para Lima (2017) segundo o levantamento da SPC Brasil, "No Brasil 79\% dos entrevistados, o compartilhamento de bens torna a vida mais fácil e funcional e $68 \%$ se imaginam participando do consumo colaborativo nos próximos dois anos". O Uber, um dos exemplos mais citados quando o assunto é economia compartilhada, experimentou um crescimento meteórico desde que chegou ao Brasil (PINELLI, 2017). A economia colaborativa tem permitido um rendimento extra àquelas pessoas que necessitam complementar sua renda, ou até mesmo, ser a única fonte de renda diante da crise de desemprego que assola o país (SALMAN, 2018).

O objetivo desse trabalho é, verificar o direcionamento da literatura brasileira, sobre o tema economia compartilhada.

Com essa revisão sistemática, pretende se observa como caminha essa temática no Brasil, trazendo uma análise atualizada sobre os recentes trabalhos brasileiros, acreditando que 
o sucesso dessa pesquisa venha a servir de instrumento acadêmico para facilitar o acesso a essas informações, que possivelmente comporte falhas e escassez de conteúdo.

\section{Metodologia}

Primeiramente, o relatório deve informar acerca da natureza da pesquisa (GIL, 2008), este trabalho tem natureza exploratória, Para Zikmund (2000), os estudos exploratórios, geralmente, são úteis para diagnosticar situações, explorar alternativas ou descobrir novas ideais. As pesquisas exploratórias têm como principal finalidade desenvolver, esclarecer e modificar conceitos e ideias, tendo em vista a formulação de problemas mais precisos ou hipóteses pesquisáveis para estudos posteriores (GIL, 2008).

De acordo com Fonseca (2002), a pesquisa proporciona uma possível identificação e um entendimento da realidade a investigar, como um processo permanentemente inacabado.

Para este trabalho foi realizado uma revisão sistemática sobre o tema economia compartilhada no Brasil.

Foi utilizado como base de dados somente o Google acadêmico, usando como chaves de pesquisa, as orações "economia compartilhada airbnb" e "economia compartilhada uber", com a finalidade de investigar o desenvolvimento dessas plataformas no Brasil, no período de 2015 a 2018, que torna relevante os últimos 4 anos, descartando trabalhos diretamente pelo título, quando esses não apresentassem palavras relacionada as chaves de pesquisa.

A escolha de somente uma base para a consulta de material se deu por conta da facilidade, por ser gratuito e por falta de artigos relevantes pra essa pesquisa em outras bases gratuitas renomadas, com uma avaliação a fundo pode se coletar o material completo para a realização da revisão, com artigos diferentes, embora englobem o mesmo tema, excluindo vários para manter o padrão, e não ser repetitivo.

$\mathrm{Na}$ base do google acadêmico quando pesquisado sobre "economia compartilhada airbnb" foi encontrado um total de 555 resultados, usando um filtro de data para os últimos 4 anos, caiu para 530 resultados, aonde foi utilizado mais dois filtros, "pesquisas em português" e "classificar por relevância", por final se totalizou um total de 220 resultados, aonde foi feito uma seleção, e 7 se adequaram a proposta utilizada por esse trabalho. 


\begin{tabular}{|c|c|c|}
\hline Autores & Título & Periódico \\
\hline $\begin{array}{l}\text { GURGEL, Camila } \\
\text { (2017) }\end{array}$ & $\begin{array}{l}\text { A intervenção e regulação estatal sobre o serviço } \\
\text { oferecido pelo airbnb no Brasil }\end{array}$ & $\begin{array}{l}\text { UFRN - Biblioteca Setorial } \\
\text { do CCSA }\end{array}$ \\
\hline $\begin{array}{l}\text { PINOTTI, Rita; } \\
\text { MORETTI, Sérgio } \\
\text { (2018) }\end{array}$ & $\begin{array}{l}\text { Hospitalidade e Intenção de recompra na Economia } \\
\text { Compartilhada: um estudo com equações estruturais em } \\
\text { meios de hospedagem alternativos }\end{array}$ & $\begin{array}{l}\text { RTA | ECA-USP | v. } 29, \text { n. } \\
1, \text { p. } 1-18, \text { jan./abr., } 2018 .\end{array}$ \\
\hline $\begin{array}{l}\text { SOARES, Andre; } \\
\text { DIAZ, Maria; } \\
\text { FILHO, Luiz (2017) }\end{array}$ & 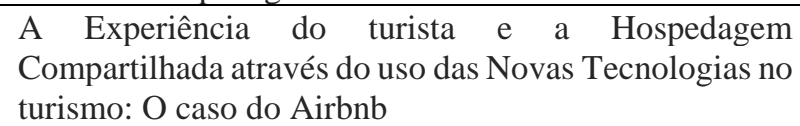 & $\begin{array}{l}\text { Revista Turismo } \quad \& \\
\text { Desenvolvimento | } \\
27 / 28 \mid 2017[1315-1324]\end{array}$ \\
\hline $\begin{array}{l}\text { GONDIM, Cibelle; } \\
\text { SEABRA, Anderson } \\
\text { (2018) }\end{array}$ & $\begin{array}{l}\text { Mídias sociais e o empoderamento de anfitriões do } \\
\text { Airbnb no Brasil: um estudo no contexto das } \\
\text { comunidades virtuais do Facebook }\end{array}$ & - \\
\hline $\begin{array}{l}\text { ALBERTINI, Giorgia } \\
(2017)\end{array}$ & $\begin{array}{l}\text { Turismo e economia colaborativa: uma avaliação das } \\
\text { plataformas online de serviços vinculados ao turismo }\end{array}$ & $\begin{array}{l}\text { Universidade Federal } \\
\text { Fluminense. Faculdade de } \\
\text { Turismo e Hotelaria, } 2017 . \\
\text { Bibliografia: f. } 82-88 .\end{array}$ \\
\hline $\begin{array}{l}\text { SILVA, Raphael } \\
\text { Andrade; } \\
\text { PAIVA, Matheus } \\
\text { Silva de; DINIZ, } \\
\text { Gustavo } \\
\text { Saad. (2017) } \\
\end{array}$ & $\begin{array}{l}\text { Desafios Jurídico-Regulatórios } \\
\text { Compartilhada: Elementos para uma Reflexão Crítica }\end{array}$ & $\begin{array}{l}\text { Scientia Iuris, } \\
\text { Londrina, v. } 21, \text { n. 2, p. } 98- \\
\text { 125, jul. } 2017 .\end{array}$ \\
\hline $\begin{array}{l}\text { SOARES, Ardyllis. } \\
\text { (2017) }\end{array}$ & $\begin{array}{l}\text { A economia compartilhada como inovação: reflexões } \\
\text { consumeristas, concorrências e regulatórias }\end{array}$ & $\begin{array}{l}\text { Revista Eletrônica da } \\
\text { Faculdade de Direito da } \\
\text { Universidade Federal de } \\
\text { Pelotas (UFPel) Vol. 03, N. } \\
\text { 1, Jan-Jun., 2017. }\end{array}$ \\
\hline
\end{tabular}

Quadro 1: Resultados encontrados no Google acadêmico.

Fonte: elaboração própria (2018)

Para "economia compartilha uber" foram encontrados 14.100 resultados, adicionando os mesmos filtros, o número final de artigos foi de 273 resultados, desses apenas 8 são relevantes para esse trabalho.

\begin{tabular}{|l|l|l|}
\hline Autores & Título & Periódico \\
\hline $\begin{array}{l}\text { OTA, Beatriz; PIAO, } \\
\text { Roberto; MELO, } \\
\text { Mary (2017) }\end{array}$ & $\begin{array}{l}\text { Uma analise do modelo de negócios de empresas de } \\
\text { economia compartilhada }\end{array}$ & $\begin{array}{l}\text { XX SEMEDAD/ } \\
\text { Seminário em } \\
\text { administração. 2017 }\end{array}$ \\
\hline $\begin{array}{l}\text { BARROS, Ana } \\
\text { (2015) }\end{array}$ & $\begin{array}{l}\text { Uber: O Consumo Colaborativo e as Lógicas do } \\
\text { Mercado1 }\end{array}$ & $\begin{array}{l}\text { COMUNICON 2015 - } \\
\text { Congresso internacional } \\
\text { comunicação e consumo }\end{array}$ \\
\hline $\begin{array}{l}\text { COELHO, Luiz; } \\
\text { SILVA, Laize; } \\
\text { ANDRADE, } \\
\begin{array}{l}\text { Mauricio; MAIA, } \\
\text { Maria (2017) }\end{array}\end{array}$ & $\begin{array}{l}\text { Perfil socioeconômico dos usuários da uber e fatores } \\
\text { relevantes que influenciam a avaliação desse serviço no } \\
\text { Brasil }\end{array}$ & $\begin{array}{l}\text { XXXI - Congressonal de pesquisa em } \\
\text { nacional } \\
\text { transporte do ANPET }\end{array}$ \\
\hline
\end{tabular}




\begin{tabular}{|c|c|c|}
\hline $\begin{array}{l}\text { SALMAN, Jamili } \\
(2018)\end{array}$ & $\begin{array}{l}\text { Inovações tecnológicas baseadas na economia } \\
\text { colaborativa ou economia compartilhada e a legislação } \\
\text { brasileira: o caso uber }\end{array}$ & $\begin{array}{l}\text { Revista de Direito, } \\
\text { Economia e } \\
\text { Desenvolvimento } \\
\text { Sustentável | Salvador | v. } \\
4 \text { | n. } 1 \text { | p. } 92-112 \mid \\
\text { Jan/Jun. } 2018 \\
\end{array}$ \\
\hline $\begin{array}{l}\text { RIBEIRO, Robson } \\
\text { (2016) }\end{array}$ & $\begin{array}{l}\text { Pensando a sustentabilidade: A economia colaborativa } \\
\text { como inovação no pensamento socioeconômico }\end{array}$ & - \\
\hline $\begin{array}{l}\text { PIERRE, Verônica } \\
\text { (2016) }\end{array}$ & $\begin{array}{l}\text { O que é meu é seu: Economia compartilhada e o } \\
\text { transporte individual. }\end{array}$ & - \\
\hline $\begin{array}{l}\text { CARNEIRO, } \\
\text { Virginia; } \\
\text { CARNEIRO, } \\
\text { valtency (2017) }\end{array}$ & $\begin{array}{l}\text { Da posse ao acesso: o papel da economia compartilhada } \\
\text { para o consumo sustentável }\end{array}$ & XIX ENGEM. Dez, 2017. \\
\hline $\begin{array}{l}\text { SAMPAIO, Luiz; } \\
\text { FISCHER, Willian; } \\
\text { MIURA, Marcio } \\
(2018)\end{array}$ & $\begin{array}{l}\text { Comportamento do consumidor na economia } \\
\text { compartilhada: Por que as pessoas participam? }\end{array}$ & $\begin{array}{l}29^{\circ} \text { ENAGRAD - Gestão } \\
\text { de aprendizagem. }\end{array}$ \\
\hline
\end{tabular}

Quadro 2: Resultados encontrados no Google acadêmico.

Fonte: elaboração própria (2018)

Com a apuração dos trabalhos, foram encontrando um total de 15 artigos, o que resultou em um total de 29 autores, com publicações que variam entre congressos (5), revistas (5) e sem periódico (5).

Segue o Quadro 3, referente o ano de publicação, das obras escolhidas.

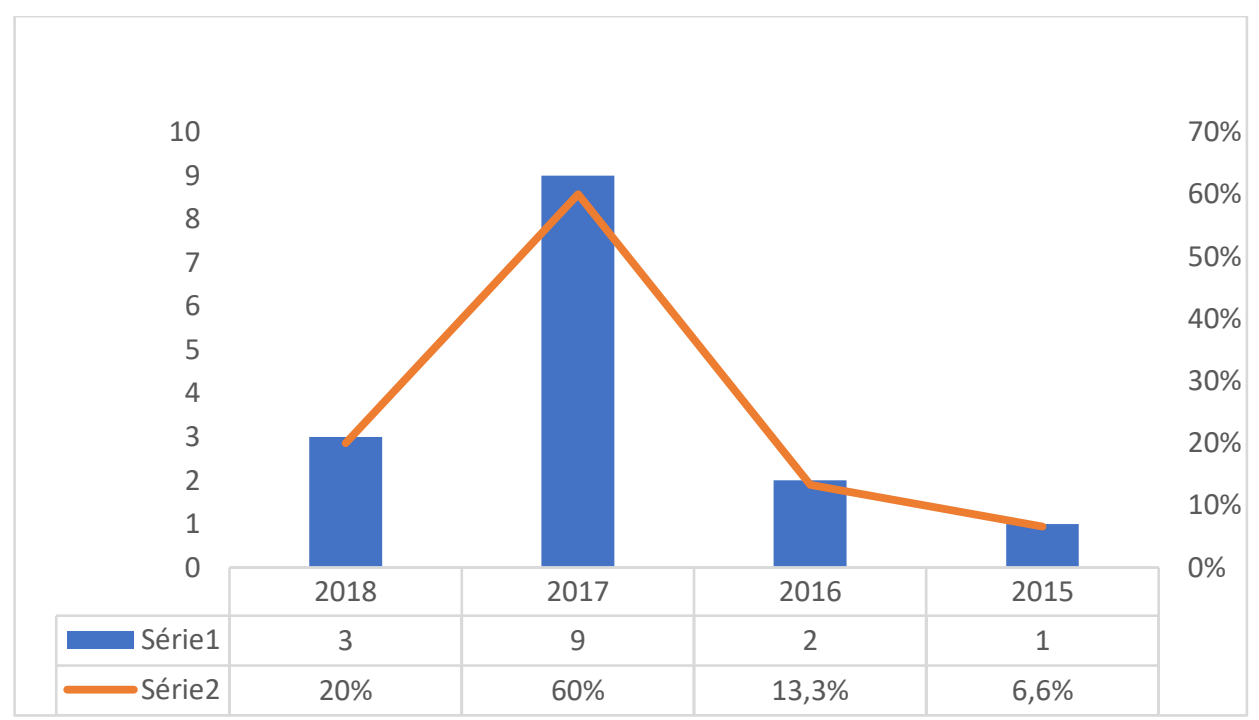

Quadro 3: Relação de artigos por ano

Fonte: elaboração própria (2018)

Desses 15 trabalhos de acordo com a data de publicação, percebe-se a saturação de trabalhos nos anos de 2017 (60\%) e 2018 (20\%), o que mostra de fato um conteúdo atualizado, 
aonde foi analisado o espaço de tempo entre 2015 a 2018, ficando da seguinte forma 2015(6,6\%), $2016(13,3 \%), 2017(6,6 \%) 2018$ (20\%).

\section{Resultados}

Para este trabalho, foi considerado o tema economia compartilhada, que possui várias características apresentadas nessa seção como, sustentabilidade, regulamentação e mercado, analisados a parti das plataformas, Airbnb e Uber.

\section{Regulamentação}

Para Gurgel (2017) ao examinar a plataforma Airbnb, pode-se verificar a forma de funcionamento em relação a sua situação legal no Brasil, em seu trabalho afirma que o processo de espaços inutilizados, parcial ou total geram uma fonte de renda excepcional, sendo também uma melhor proposta para clientes desse segmento, resultado alcançado devido à falta de regulamentação que é visto como uma falha de mercado, que requer a intervenção estatal, devido ao fato que a natureza do negócio praticada pelo o Airbnb, não difere dos serviços prestados pelas empresas hoteleiras, em contrapartida difere no tocante a fiscalização que não ocorre nessas ferramentas inovadoras, e propõem um concorrência desleal.

Entende no trabalho de Salman (2018) sobre a legalidade de fato do Uber, baseado no artigo $5^{\circ}$, XIII da CF/1988, o qual estabelece que "é livre o exercício de qualquer trabalho, ofício ou profissão, atendidas as qualificações profissionais que a lei estabelecer.”. no entendimento deste trabalho úberes não são confundidos com taxistas, desde que um é intermediário de serviços e negócios, e taxistas é serviço de taxi, lembrando que o uber não é uma empresa de transportes, seu serviço é prestado por prestadores independentes de ser funcionários uber, o que a empresa faz é apenas ligar os pontos com técnicas de intermediação P2P. Para o autor o que acontece é um vácuo legislativo, pois o uber não é ilegal e em contra partida fere o direito básico de convívio social, como relatado em seu trabalho as ocorrências de conflitos entre taxistas e uber, alegando uma concorrência desleal, que de certa forma não é ilegal. 
Já Silva et al. (2017) alega que o direito não acompanha temas voltados a inovação, e com isso encontra-se vulnerável para lidar com a economia compartilhada, ainda mais depois de sua expressividade ganhada nos últimos anos. A falta de pesquisa no âmbito jurídico atrasa ainda mais o processo, grande parte dessa culpa parte também da não iniciativa dessas empresas envolvidas, que pouco investem em pesquisas de desenvolvimento $(\mathrm{P} \& \mathrm{D})$ nessa área.

Silva et al. (2017) acredita que se trata de um fator equacional, aonde é preciso colocar em evidencia ambos os lados, negativo e positivo, e avaliar esses lados e seus efeitos diretos e indiretos na sociedade, se preocupando exclusivamente com o consumidor, que tem que ser beneficiado. Para isso deve-se haver uma resposta estatal a esse mercado, para que o estado também seja beneficiado através de uma legislação eficiente.

Soares (2017) defende em seu trabalho tratando das regulamentações desse sistema, o incentivo para a ascensão desse mercado, retratando seus benefícios como a diversidade de serviços, barateamento dos preços concorrentes, sustentabilidade ambiental, informalidade atrativa, público altruísta, e facilidade de entrada baseado nos seus custos.

Soares (2017) retrata a capital da coreia do sul, Seul e o seu projeto chamado Sharing city seul initiative, trata-se do próprio governo fomentando o desenvolvimento de 63 tipos de serviços compartilhados, o que difere a situação brasileira, que ainda ver essa situação como falha de mercado.

\section{Sustentabilidade}

Sustentabilidade é um termo usado para definir ações e atividades humanas que visam suprir as necessidades atuais dos seres humanos, sem comprometer o futuro das próximas gerações. (RIBEIRO, 2017)

Para Carneiro (2017) a economia compartilhada veio desaparelhar os hábitos consumistas enaltecidos pelo status da posse, o que mostra a irresponsabilidade do consumo pragmático, que reforça o sistema capitalista. Nessa discussão sobre consumo sustentável aliada a economia compartilhada, alega-se o fato dessa relação acontecer indiretamente e não ser uma característica principal desse mercado, deve se haver o discurso público da parte das empresas compartilhadas, para que os consumidores tenham conhecimento do efeito negativo causado desse estilo de vida da posse, e se tornem o autor social, aptos a ideia de compartilhamento, por 
uma causa sustentável. Pois é preciso ser cidadão além de consumidor para entender o papel social do consumo e é preciso ser um cidadão organizado em rede, para alcançar causas coletivas (CARNEIRO, 2017).

O trabalho de Carneiro (2017) mostra a importância da economia compartilhada para a mitigação dos impactos ambientais, e alerta como a economia compartilhada pode servir de discurso político, para a disseminação da ideia de consumo sustentável.

A economia tradicional de ter a posse do produto, a base dos moldes capitalistas por muitas vezes é relacionada ao consumo irresponsável que resulta no fim dos recursos naturais tão fundamentais para a vida. A economia compartilhada chega pra suprir essa demanda entre capitalismo e socialismo, com ideia de valorizar a distribuição do capital entre as pontas desse mercado (RIBEIRO, 2017).

Com tudo Ribeiro (2017), nos mostra exemplos de como tem funcionado outras ferramentas consideradas conflitantes para seus concorrentes. "A guerra travada pela indústria da música contra o Napster, programa de compartilhamento de músicas, provou que uma aparente vitória legal foi, na verdade, uma derrota na prática, pois o compartilhamento de músicas aumentou de forma alarmante."

O livro digital não matou o livro físico, pelo contrário influenciou no aumento de vendas, graças aos serviços de streaming, as pessoas voltaram a pagar para escutar músicas, chegando à conclusão que esse método compartilhado pode não interferir no modelo tradicional, contrariando a ideia da tecnologia disruptivo, deixando claro que nem todos os casos são iguais (RIBEIRO, 2017).

Para Sampaio (2017) em seu estudo afirma que a sustentabilidade não influencia nas atitudes desse público, ressaltando que os benefícios econômicos são os principais influenciadores para o uso da economia compartilhada. Essa pesquisa feita dentro do ambiente em que o consumo colaborativo é a base do relacionamento entres os participantes, através de uma modelagem de equações estruturais que partia da hipótese que existe fatoriais para a participação das pessoas na economia compartilhada, que são Sustentabilidade, Satisfação, Reputação e Benefícios Econômicos, 


\section{Mercado}

O mundo tornou-se mais dinâmico, as mudanças passaram a ser mais constantes e mais rápidas, o surgimento e a posterior evolução da internet permitiram conectar o mundo inteiro, possibilitando comunicações de longa distância e em alta velocidade (COSTA, 2016)

Para Alves (2017) o que explica sua oferta é, uma experiencia nova e de fácil acesso em um mercado que possui grande atratividade e percepção de inovação, além disso percebe se o baixo custo para entrantes, em muitas vezes o custo é zero. "Uma renda extra, sem mudança súbita no perfil econômico da pessoa envolvida".

O estudo de caso feito por Ota et al. (2017) traz um conteúdo mais detalhado em questão aos entrantes desse mercado, ao retratar 3 empresas que trabalham com plataformas compartilhadas, aonde chama a atenção a semelhança entre elas, todas conectadas em rede. Afirmando que esse tipo de negócio, diferente dos tradicionais, não exige um grande capital, sendo assim um baixo custo para entrantes, nos demais essas empresas compartilhadas investem como uma empresa tradicional, agregando ao negócio marketing, acessibilidade e canais de comunicação, exigindo menos recursos físicos e humanos, voltando sua preocupação ao máximo em inovação, que é peça fundamental nesse segmento.

As três empresas estudadas por Ota et al. (2017) se encaixaram na relação B2C (empresa para consumidor), afirmando que o mais importante para o negócio é o consumidor final, lucrando em cima de transações com pequenas comissões intermediada por essas empresas, entre os prestadores de serviço e esses clientes ociosos.

No tocante ao Uber, Pierre (2016) em sua pesquisa retrata entre os principais sistemas de transporte individual, afirmando que apenas o Uber possui o perfil da economia compartilhada, empreendedorismo e inovação, além de ter o melhor serviço disparado na frente de seus principais concorrentes o 99taxi e o Easytaxi, que causam insatisfação devido ao seu alto custo de serviço.

Para Barros (2015) o compartilhamento é algo inovador e essencial, afirmando em seu trabalho a necessidade desse mercado para o benefício ao consumidor, que é o fator primordial para não se haver uma regulamentação concreta, em relação aos casos judiciais que ocorrem, um exemplo disso o Uber no Brasil. O Uber tem um sistema único, alegando que a ferramentas tende a ser suficiente para dar uma escolha nova ao consumidor, tem a capacidade de aproveitar 
algo que não estava sendo utilizado, promove a crença sobre o equilíbrio sustentável, e tem a capacidade para gerar confiança entre estranhos.

O trabalho de Coelho (2017) identificou a percepção de qualidade em relação a ferramenta compartilhada Uber. O trabalho em questão, relatou que o público que mais utiliza desse meio são jovens, com melhores condições financeiras, concluindo que esse público tende a experimentar novidades e muitas já tem afinidade com o transporte individual, com a pesquisa também foi possível identificar características relevantes, onde a segurança ficou em primeiro lugar, comodidade em segundo, preço do serviço em terceiro.

Pinotti e Moretti (2018) ao investigar o caso sobre os principais influenciadores para a recompra de hospedagem, o indicador em destaque em sua análise estrutural foi a percepção de prazer, alegando o fato de ter aspectos padronizados como segurança, empatia, boa vontade e conformidade com o contratado.

E normal quando se pergunta a um cliente desse modelo, o que o deixa tão atrativo, eles respondem segurança e comodidade, mesmo advindo da internet palco de grandes fraudes. $\mathrm{Na}$ pesquisa de Soares et al. (2017) ao coletar comentários desses clientes, pode-se observa o comportamento dos mesmos, ao selecionar somente as palavras mais utilizadas por esses, foi possível identificar sentimentos caseiros e laços de amizades, que vão além do processo mecânico de hospedar.

Gondim (2017) destaca a mídia social como forma de conseguir feedback de pessoas que entendem do assunto, e tem interesse em comuns, isso parte de anfitrião para anfitrião, com a finalidade de conseguir empoderamento como diferencial e destaque entre os demais, o chega próximo de um ambiente coorporativo, essa manifestação parte do incentivo direto dessas empresas compartilhadas com canais de host voice, que são grupos, comunidades com o objetivo de conseguir novos membros e a permanência dos existentes.

Com o surgimento das novas empresas compartilhadas Albertini (2017) fala da remodelação que sofre o turismo por conta disso, e a preocupação dos modelos tradicionais com essas ferramentas tecnológicas, que muitas vezes não possuem nem custo de entrada. Os segmentos aliados ao turismo como alimentação, hospedagem, e guias turísticos, já se utilizam de ferramentas compartilhadas, trazendo uma experiencia autentica "O Airbnb deixou de ser uma plataforma que oferece apenas acomodação e hoje oferece também vários tipos de experiência." Concluindo-se que, a economia compartilhada através de suas ferramentas como exemplo Airbnb, incentivam o turismo de forma perceptível, com a afirmativa que a demanda 
por serviços da empresa Airbnb, já ultrapassam as maiores redes hoteleiras do mercado tradicional.

\section{Conclusão}

Conclui-se com a revisão sistemática, uma evolução relativa aos últimos 2 anos, em respeito ao tema economia compartilha voltado ao setor de serviço, que foi o foco principal para esse trabalho. Embora a vasta possibilidade de explanação da temática no Brasil, muitos desses trabalhos escritos ainda são baseados em situações internacionais e escritores estrangeiros, o que demonstra a escassez de trabalhos brasileiro em relação a temática.

Ao analisa os trabalhos brasileiros, foi possível destacar o principal embate, sendo comentado em todos os trabalhos a questão da regulamentação brasileira. Através da tecnologia e inovação proporcionado por essas ferramentas, a legislação caminha desconexa com situação atual, o que sugere um possível descaso em relação a pesquisas e discussões sobre o que fazer com esse mercado disruptivo. Em contrapartida em alguns momentos os autores defenderam a necessidade desse modelo inovador, por conta de suas propostas sustentáveis, uma nova fonte econômica e o benefício direto ao consumidor final que é o principal benificiário da situação.

Contudo o legislativo deve se manter atento em relação a sua regulamentação, definindo fiscalizações devidamente corretas a esse grupo de empresas compartilhadas, para que além da população, o estado venha a se beneficiar, o que não diminuir a ideia de uma regulamentação para um concorrência sadia, crescendo e aproveitando os dois lados, o inovador e o tradicional

No aspecto sustentabilidade em seu debate, houve a falta de posicionamento concreto, para definir se é sustentável ou não, embora concluiu-se que ocorre sim a sustentabilidade, mas de forma indireta, chegando à conclusão que falta iniciativa privada, em seu papel de incrementar o discurso do consumo sustentável, visando a mudança de hábitos tradicionais, resultando na casualidade de pessoas participando da economia compartilhada por uma causa sustentável, desaparelhando o sistema capitalista baseado em ter a posse, o que propõe a preservação dos recursos naturais. 


\section{Referências}

ALBERTINI, Giorgia. Turismo e economia colaborativa: uma avaliação das plataformas online de serviços vinculados ao turismo. Disponível em: https://app.uff.br/riuff/handle/ 1/4721 Acesso em: (27 set, 2018).

ALVES, Ardyllis. A economia compartilhada como inovação: reflexões consumeristas, concorrências e regulatórias, Revista Eletrônica da Faculdade de Direito da Universidade Federal de Pelotas (UFPel), Pelotas, Vol. 03, N. 1, Jan-jun., 2017.

BARROS, Ana. Uber: O Consumo Colaborativo e as Lógicas do Mercado. In: Anais do $5^{\circ}$ Encontro de GTs do Comunicon. 2015.

CARNEIRO, Virginia; CARNEIRO, valtency. Da posse ao acesso: o papel da Economia Compartilhada para o Consumo Sustentável. In: XIX ENGEM. Dez, 2017.

CLAY, Shirky. Lá vem todo mundo: o poder de organizar sem organizações. Zahar, Rio de janeiro, 2012.

COELHO, Luiz; SILVA, Laize; ANDRADE, Mauricio; MAIA, Maria. Perfil socioeconômico dos usuários da uber e fatores relevantes que influenciam a avaliação desse serviço no brasil. In: CONGRESSO DE PESQUISA E ENSINO EM TRANSPORTES. 2017.

FONSECA, João. Metodologia da pesquisa científica. Fortaleza: UEC, 2002.

GANSKY, Lisa. The mesh: why the future of business is sharing. USA: Penguin, 2010.

GIL, Carlos. Métodos e técnicas de pesquisa social. 6. ed. São Paulo: Atlas, 2008.

GONDIM, Cibelle; SEABRA, Anderson. Mídias sociais e o empoderamento de anfitriões do Airbnb no Brasil: um estudo no contexto das comunidades virtuais do Facebook. Disponível em: https://www.researchgate.net/publication/327190717 _Midias_sociais _e_o_empoderamento_de_anfitrioes_do_Airbnb_no_Brasil_um_estudo_no_contexto_das_co munidades_virtuais_do_Facebook. Acesso em: (26 set, 2018).

GURGEL, Camila. A intervenção e regulação estatal sobre o serviço oferecido pelo Airbnb no Brasil. 2017. 72 f. Monografia (Especialização em Direito Administrativo) - Universidade Federal do Rio Grande do Norte, Centro de Ciências Sociais Aplicadas, Programa de PósGraduação em Direito. Natal, RN, 2017.

LIMA, Mariana. Economia compartilhada é bem vista por $79 \%$ dos brasileiros. Disponível em: <http://www.portalnovarejo.com.br/2017/08/10/economia-compartilhada-e-bem-vistapor-79-dos-brasileiros/> Acesso em: 19 mai, 2018

OTA, Beatriz; PIAO, Roberto; MELO, Mary. Uma análise do modelo de negócios de empresas de economia compartilhada, In: XX SEMEDAD/ Seminário em administração. 2017. 
PIERRE, Verônica. O Que é meu é seu: A Economia Compartilhada e o Transporte Individual. Dissertação (Trabalho de Conclusão de Curso) - Faculdade de Tecnologia e Ciências Sociais, Brasília, 2016.

PINELLI, Natasha. Economia Compartilhada. Disponivel em: <https://epocanegocios.globo .com/Caminhos-para-o-futuro/Desenvolvimento/noticia/2017/01/economia-compartilhada .html> Acesso em: 19 mai, 2018

PINOTTI, Rita; MORETTI, Sérgio. Hospitalidade e Intenção de recompra na Economia Compartilhada: um estudo com equações estruturais em meios de hospedagem alternativos, RTA | ECA-USP, v. 29, n. 1, p. 1-18, jan./abr., 2018.

RIBEIRO, Robson. Pensando a sustentabilidade: A economia colaborativa como inovação no pensamento socioeconômico. Disponível em: <http://siepps.uea.edu.br /siepps2/assets/pdf/artigos/GT7-ARTIGOCOMPLETO0512Robson\%20Parente.pdf> Acesso em: (27 set, 2018).

SALMAN, Jamili. Inovações tecnológicas baseadas na economia colaborativa ou economia compartilhada e a legislação brasileira: o caso uber, Revista de Direito, Economia e Desenvolvimento Sustentável, Salvador, v. 4, n. 1, p.92 - 112, Jan/Jun. 2018

SAMPAIO, Luiz; FISCHER, Willian; MIURA, Marcio. Comportamento do consumidor na economia compartilhada: Por que as pessoas participam? In: $\mathbf{2 9}^{\circ}$ ENAGRAD - Gestão de aprendizagem. 2018.

SILVA, Raphael; PAIVA, Matheus; DINIZ, Gustavo. Desafios Jurídico-Regulatórios e Economia Compartilhada: Elementos para uma Reflexão Crítica, Scientia Iuris, Londrina, v. 21, n. 2, p. 98-125, jul. 2017.

SOARES, Andre; DIAZ, Maria; FILHO, Luiz. A Experiência do turista e a Hospedagem Compartilhada através do uso das Novas Tecnologias no turismo: O caso do Airbnb, Revista Turismo \& Desenvolvimento, n.o 27/28, p.1315 -1324, 2017.

SCHOR, J. Debating the sharing economy. 2014. Disponível em: <http://greattransition.org/ publication/debating-the-sharing-economy>. Acesso em: 03 abr. 2018.

ZIKMUND, W. G. Business research methods. 5.ed. Fort Worth, TX: Dryden, 2000.

\section{Como citar este artigo (Formato ABNT):}

OLIVEIRA, Luiz Nayjhon de Souza; LIMA, Antônio Raniel Silva. Economia compartilhada aliado ao setor de serviços: uma revisão sistemática de trabalho brasileiros. Id on Line Rev.Mult. Psic., 2018, vol.12, n.42, Supl. 1, p. 365-377. ISSN: 1981-1179. 